\title{
El hilo del que está tejido el manto de Celestina*
}

\author{
Mariel Aldonza Palma Villaverde \\ Universidad Nacional Autónoma de México
}

En los siglos I y II d.C., los tratadistas latinos definían al textum (texto) como una tela perfecta que el escritor tejía con las palabras: era perfecta porque no se notaba el hilado del que estaba hecha. La Celestina, a la luz de esta consideración, es un texto que se teje con los diálogos de los personajes —o vidas como ha optado por llamarlos Stephen Gilman -1, quienes con su voz crean y entrelazan los muchos hilos discursivos de la trama. ${ }^{2}$ Uno de estos hilos es el que forman las unidades léxicas referentes al vestido, las cuales abundan en la obra y la recorren de principio a fin. En la Celestina, el vestido funciona como pago, como esperanza y como motor; también como recurso discursivo o como objeto de traición. Las prendas de vestir están entretejidas en los diálogos de todos los personajes y por lo tanto en su vida, pues como la lengua y el discurso, el vestido tiene su propia historia y sus propios cambios de significado en cuanto función social. En la época de Rojas, el vestido era un elemento tan importante en la vida social que la gente gastaba grandes sumas de dinero en un atuendo, y se perdían y empeñaban fortunas con tal de mantener o aparentar un estado de prosperidad.

El vestido, tal como la palabra, oculta y revela; muestra (demuestra), pero también esconde. En la Celestina, algunas de las unidades léxicas re-

\section{1.- Cf. Stephen Gilman, La Celestina: arte y estructura, Madrid, Taurus, 1974.}

2.- Según Rosario Ferré, existe en la obra una gran metáfora primaria o madre que es la metáfora del hilado, de la cual derivan metáforas secundarias que construyen la red discursiva del texto: «Las metáforas secundarias derivadas del hilado son las siguientes: cordón-sábanasaguja-cadena de oro. A estas metáforas habría que añadir [...] el jubón que Calisto le regala a Sempronio; el manto y saya que Calisto le promete a Celestina (y que Celestina luego le promete a Pármeno); y la saya que Melibea le promete a Celestina». (Rosario Ferré, "Celestina en el tejido de la Cupíditas", Celestinesca 7 (1983), p. 7). Estas metáforas secundarias demuestran que las unidades léxicas «independientes» pueden ser consideradas como un hilo discursivo que también teje la acción. Mercedes Alcalá Galán, por su parte, afirma que el texto es «una red casi invisible de alianzas y traiciones, obsesiones, voluntades, usurpaciones [...] todo ello marcado por un rabioso individualismo que hará inevitable el caos y el aniquilamiento del mundo en miniatura que se refleja en Celestina». (Mercedes Alcalá Galán, «Voluntad de poder en Celestina», Celestinesca 20 (1996), p 38).

* Este artículo se incluye en Internet modificado, a causa de imprimirse en papel con erratas sin corregir por fallos del editor. 
ferentes al vestido cumplen con esta función, pues no sólo acompañan la acción del texto, sino que muchas veces son catalizadores de los deseos ocultos de los personajes y tienen distintos significados a lo largo de la obra. Tal es el caso de las unidades léxicas en las que se concentra este estudio, que son las haldas - saya/manto de Celestina, y su función en el devenir discursivo de la vieja alcahueta, porque palabra y vestido están cosidos en su discurso como elementos que determinan su destino.

Entonces, la unidad léxica haldas significará, a grandes rasgos y como primer nivel de categorización, el presente en que Celestina se encuentra. En consecuencia, la unidad léxica manto, en relación directa con la unidad haldas, significará el futuro al que Celestina pretende llegar con el negocio entre Calisto y Melibea. Estas unidades son inseparables una de otra y también de la red discursiva del texto. Como tales, forman un proceso que ahonda tanto en las situaciones discursivas, como en la sustancia y en la forma del discurso de Celestina. ${ }^{3}$ Cuando una de estas unidades se menciona, ocupa un espacio y una temporalidad en la trama, por lo que no siempre tienen la misma función en el texto, y parten de un significado general.

Así pues, tendremos que las funciones discursivas de estas unidades léxicas estarán determinadas por su valor o contenido, que son los siguientes:

\section{SignifiCADO GENERAL}

Significa el desamparo económico y espiritual en el que Celestina se encuentra. Este significado envuelve y determina a los significados primordial y circunstancial, que no son menores en cuanto a valor discursivo. Ubicamos a la unidad léxica manto en este nivel porque determina el devenir discursivo de Celestina.

\section{SignifiCADO PRIMORDIAL}

Es el movimiento o proceso de las unidades léxicas haldas - sayal manto. Sin embargo, cada unidad tiene su propio valor primordial, así, tendremos que:

a) Haldas: En este nivel las haldas significan y representan el oficio de Celestina. Discursivamente son el elemento aliado que la acompaña en la red de pasos que teje entre su estado actual $y$ al que pretende llegar con el negocio.

3.- Las acepciones de discurso usadas en este trabajo siguen aquellas propuestas por Albert Lloret en su trabajo «El error retórico de la alcahueta. Performatividad y nueva retórica en la Celestina». El estudioso propone una serie de elementos encaminados a descubrir la situación argumentativa, la sustancia de esta situación y el objetivo del argumento. Véase Albert Lloret, «El error retórico de la alcahueta. Performatividad y nueva retórica en la Celestina», Celestinesca 31 (2007), pp. 119-132. 
b) Manto: En este nivel significa la codicia económica de la vieja alcahueta y la parte indivisible del negocio que, irónicamente, la llevará a su fracaso discursivo.

Los incisos $a$ y $b$ se entretejen mediante la unidad saya, que significa a grandes rasgos un estado transitorio entre los significados primordiales de las haldas y el manto.

\section{Significado CIRCUNSTANCIAL}

Los significados general y primordial se amplían dependiendo del momento textual/discursivo de Celestina, así como de su estado emocional y del diálogo con uno u otro personaje o bien consigo misma.

Así pues, cada mención parte del significado general; por su posición en el texto, este significado general sumará uno primordial, que se vuelve más puntual mediante su valor circunstancial. Estas unidades, además de símbolo, son a la vez un hecho lingüístico.

A continuación se ofrece un análisis de las unidades léxicas haldas - saya/manto de Celestina bajo los parámetros que acabamos de mencionar. Este análisis se basa fundamentalmente en el significado circunstancial que adquiere cada unidad léxica durante cada mención. Si bien la primera unidad de nuestro hilo discursivo es manto, para los fines que persigue este estudio, analizaremos primero la unidad haldas.

\section{Las haldas}

Dado que la Celestina carece de narrador, los personajes son los encargados de crear el texto. Dependemos de su punto de vista para entender y cuestionarnos su mundo. En nuestra obra no existen grandes descripciones y, por el contrario, la realidad extralingüística de los personajes parece estar, también, sometida a su punto de vista. Así pues, la primera aparición de la unidad léxica haldas tiene lugar en el auto Iv. Antes de ello, lo único que sabemos acerca del vestido de Celestina es que ésta lleva un manto, apenas mencionado por Sempronio en el auto I. La atención se ha enfocado en las "cualidades» de la vieja, las cuales nos permitirán entender los significados circunstanciales de cada prenda y con qué otros elementos se tejen, y si éstas son causa o agente de algunas de las acciones posteriores.

Existen en total cinco menciones a la unidad haldas ${ }^{4}$ todas en boca de la propia Celestina. Cuatro de ellas aparecen entre el auto Iv y v, y la última

4.- Como toda producción discursiva, La Celestina dialogará forzosamente con tradiciones literarias, discursivas e indumentales. Conocer cómo era la vestimenta en aquella época arroja datos harto significativos. Por ejemplo, respecto a la unidad haldas, sabemos que ésta no era 
muy lejos de estas apariciones, en el auto xI, ya muy cerca de su muerte. Existen además dos menciones a la acción de las haldas, esto es, el verbo haldear. Esta acción será reconocida por agentes externos y nunca enunciada por Celestina.

Cuando la unidad haldas aparece, la situación discursiva de Celestina es la siguiente: Celestina se ha aliado con Sempronio y ha "aceptado» las condiciones que éste la ha puesto. Por otro lado, Celestina descubre que tiene que buscar la manera en que Pármeno no sea una molestia para la realización del negocio y decide darle un pago a cambio de que éste prometa amistad con Sempronio. Además, Celestina se ha entrevistado con Calisto y le ha prometido que ella será la encargada de recuperar su palabra perdida.

Hasta aquí, la vieja alcahueta se ha presentado ante Calisto, Pármeno y Sempronio, como una maestra de la palabra. Sin embargo, al inicio del auto IV, encontramos a una Celestina que, por fin sola, "habla» consigo misma, reconociendo ante sí misma los temores que tenía ocultos acerca del negocio. María Teresa Miaja de la Peña, en su artículo "Agora que voy sola...' en boca de Celestina», 5 explica que la vieja aprovecha este momento de soledad para ponderar los pros y los contras de su empresa, y después de que, como afirma Josep T. Snow, ${ }^{6}$ ha encontrado el motivo que le dará fuerza para seguir con el negocio, ésta menciona sus haldas por primera vez: "las piedras parece que se apartan y me hacen lugar a

una prenda individual como en nuestros tiempos, sino que pertenecía a la estructura completa de la saya. Ésta era una prenda semi-interior que «se diferenciaba de los trajes de encima como mongiles, hábitos y ropas, en que no era un traje holgado como ellos, sino ceñido al cuerpo». (Carmen Bernis, Trajes y modas en la España de los Reyes Católicos, Volumen II, Madrid, Instituto Diego Velázquez del Consejo Superior de Investigaciones Científicas, 1979, p. 120.) Por su parte, Sebastián de Covarrubias distingue el verbo que atañe a la falda: «falda: recoger las faldas para andar más desembuelto, que vulgarmente decimos poner faldas en cinta, [tal como Sempronio] y es determinarse deveras a hazer alguna cosa con mucha ligencia, tomada la semejança de los que avían de caminar, que se enfaldavan recogiendo las faldas en la cinta, como agora haen los religiosos que caminan a pie. Enfaldarse la muger, recoger sus sayas para andar más ligera». (Sebastián de Covarrubias Orozco, Nuevo tesoro de la lengua castellana o española, Madrid, Castalia, 1995, p. 395). Los paréntesis son míos. Por su parte, Fray Hernando de Talavera apunta, acerca de las haldas: "Cuando las mujeres se ocupan en servicios y oficios humildes, alzan y remangan las faldas de la saya porque no les haya de ensuziar, y para guardar la honestidad y quedar cubiertas las piernas suplen allí las faldetas de vil y grueso paño». (Fray Hernando de Talavera, Tratado de los pecados que se cometen en el vestir, en Ibíd., p. 89).

5.- Cf. María Teresa Miaja de la Peña, "Agora que voy sola...' en boca de Celestina», Olivar: Revista de Literatura y Culturas Españolas 11 (2008), pp. 27-37.

6.- Josep T. Snow plantea que el motivo por el que Celestina decide ir finalmente a casa de Melibea se encuentra en la frase: «Más quiero ofender a Pleberio que enojar a Calisto». Véase, Josep T. Snow, "Quinientos años de animadversión entre Celestina y Pleberio: postulados y perspectivas», Visiones y crónicas medievales. Actas de la VII Jornadas Medievales, eds. Aurelio González, Lillian von der Walde y Concepción Company, México, Universidad Nacional Autónoma de México - Universidad Autónoma Metropolitana - El Colegio de México, 2002, pp. 13-29. 
que passe; ni me estorvan las haldas ni siento cansancio al andar; todos me saludan. Ni perro me ha ladrado, ni ave negra he visto, ni tordo ni cuervo ni otras noturnas»?

Celestina se refiere a sus haldas como un elemento que le pesa, pues es una unidad que, primordialmente, significa su oficio. En un significado general, podemos ver que éstas son las haldas que viste la mujer barbuda, la de la cuchillada; aquella que está ya muy mudada por la edad. Sin embargo, Celestina siente ahora una fuerza interior que la impulsa a seguir adelante con el negocio y que se manifiesta en distintas señales favorables, como sentir ligeras sus haldas. Es decir, los significados general y primordial se amplían en esta nueva circunstancia o motivo para seguir adelante con su empresa.

Esta mención, pues, establecerá una inmediata conexión con la siguiente, que es angular para este estudio: «Pues alégrate, vieja, que más sacarás deste pleito que de quinze virgos que renovaras. ¡ $\mathrm{O}$ malditas haldas, prolixas y largas, cómo me estorváys de allegar a donde han de reposar mis nuevas!» (v, 175)

Ha pasado algo muy importante entre estas dos menciones. Celestina ha podido entrar a casa de Melibea y ha asegurado su vuelta. En este momento Celestina ya no ve en sus haldas solamente un signo favorable, sino el presente que comienza a molestarle cada vez más, porque es un presente de lazería, de pelo malo que según Pármeno «ni en cincuenta años ha podido medrar» (vI, 182). Éstas son las haldas que viste la mujer que ha sido empicotada y emplumada, y que, además, han recibido la furia de Melibea. Pero circunstancialmente, Celestina comienza a arroparse con los hechos que tendrían que suceder como consecuencia lógica del negocio, o sea, con la obtención del manto, que la arropará en su última edad. Es decir, que el motivo que le dio fuerza para llegar a casa de Melibea, ahora se ha transmutado en un claro objetivo. El significado general de haldas-saya/manto y estos circunstanciales de la unidad haldas, se unen en un hiato temporal con la unidad manto, y adelantan la acción, puesto que, precisamente, Celestina le pedirá a Calisto un manto como pago por sus servicios.

Vemos, pues, que los significados circunstanciales progresan y se van hilando indefectiblemente con acciones posteriores o anteriores. Además, esta segunda aparición de la unidad haldas sucede también en un monólogo, con lo cual podemos ver la sustancia del discurso individual de Celestina y entender desde dónde comienza a fraguar la traición hacia Pármeno y a Sempronio.

7.- Fernando de Rojas, La Celestina, ed. de Dorothy Severin, Madrid, Cátedra, 2008. A partir de este momento, los números romanos indicarán el auto, mientras que los arábigos la página. En este caso iv, 154. 
Pues bien, llena de sí misma y del buen resultado que parece que tendrán sus pasos, Celestina pone más atención en el acto lingüístico que en su sustancia. Es decir, el sentimiento de codicia que surge en su interior no la dejará ver que hay otros intereses zurcidos a los suyos. Dice Celestina: "Por esto dizen que quien las sabe las tañe, y que es más cierto el médico sperimentado que el letrado, y la esperiencia y el escarmiento haze los hombres arteros, y la vieja, como yo, que alce sus haldas al passar el vado, como maestra» (v, 176). Esta tercera mención refuerza el significado circunstancial de las anteriores porque confirma la fuerza interior que siente la vieja.

Hasta ahora, solamente ha "hablado» consigo misma, y ha decidido —aunque aún no explícitamente-que el pago que demandará a Calisto tiene que ser indivisible. A partir de aquí, el discurso de Celestina hacia Pármeno y Sempronio estará encaminado a engañarlos, mientras que el que dirigirá a Calisto, será perfectamente pensado y atinado. Así pues, surge una partícula determinante para comprender nuestro hilo discursivo: la acción de haldear, que significa primordialmente, en sus dos apariciones, la prisa que la vieja alcahueta lleva.

Celestina se da a notar por esta acción y Lucrecia se pregunta: «¿Quién es esta vieja que viene haldeando?» (IV, 155). Con lo que la acción de sus haldas precede a la primera mención de la unidad léxica. Aquí el verbo funciona como una especie de reconocimiento para Lucrecia, y para Sempronio funciona como revelación: «O yo no veo bien, o aquella es Celestina. ¡Válala el diablo, haldear que trahae! Parlando viene entre dientes» (vI, 176).

Esta acción descubre a Sempronio que algo inusual pasa, y dice a la vieja:

La raleza de las cosas es madre de la admiración; la admiración concebida en los ojos desciende al ánimo por ellos, el ánimo es forçado descobrillo por estas exteriores señales. ¿Quién jamás te vido por la calle, abaxada la cabeza, puestos los ojos en el suelo, y no mirar a ninguno como agora? ¿Quién te vido hablar entre dientes por las calles y venir aguijando, como quien va a ganar beneficio? Cata que todo esto novedad es para se maravillar quien te conoce. ( $\mathrm{v}, 176)$

Este momento o situación discursiva es muy importante, porque Celestina verbalizará lo que pasa en su interior y cometerá el error de llamar "partezilla» a la parte del negocio que en teoría correspondía a Pármeno y a Sempronio. Este último le dice a la vieja: «¿Partezilla, Celestina? Mal me parece esso que dizes» (v, 177), a lo que ésta contesta: "Calla, loquillo, que parte o partezilla quanto tú quisieres te daré. Todo lo mío es tuyo; gozémonos y aprovechémonos, que sobre el partir nunca reñiremos» (v, 177). 
Así pues, con este diálogo podremos entender que los significados circunstanciales de las unidades hasta aquí mencionadas, establecen desde este momento el destino de Celestina en tanto que:

1) Celestina construye dos tipos de discursos en cuanto al negocio:

a) El que está dirigido a Calisto, el cual implica distancia económica, y se produce en un nivel que incluye fórmulas de tratamiento, tópicos y motivos literarios.

b) El que compete a Pármeno y a Sempronio. Con cada uno manejará un discurso diferente, pero a partir de que aparece la unidad léxica haldas, el discurso de la vieja en cuanto al negocio incluirá a ambos sirvientes, si no en un mismo nivel discursivo, sí en una misma esfera. Este discurso, a diferencia del que dirige a Calisto, se mueve sobre la familiaridad y a un mismo nivel económico.

2) Celestina no tiene en cuenta a Sempronio y a Pármeno de la misma manera que tiene en cuenta a Calisto, y no pone cuidado en tejer su discurso de manera en que éste cubra con maestría sus intenciones.

3) En nuestra obra ceguedad significa perder el seso y Celestina lo ha demostrado con la palabra "partezilla» justo después de que ha venido haldeando a casa de Calisto.

Así pues, cuando Celestina lleva consigo la buena palabra de Melibea (la palabra recuperada), las haldas aparecen por cuarta ocasión, y esta vez, su significado está dirigido a Sempronio: «¿Qué dizes Sempronio? ¿Con quién hablas? ¿Viénesme royendo las haldas? ¿Por qué no aguijas?» (v, 178).

La unidad léxica haldas funciona aquí como una metáfora, según Peter Rusell: «royendo las haldas: entiéndase aquí, caminando por detrás; [...] hay un posible doble sentido puesto que roer los zancajos significa murmurar, decir mal de alguna». ${ }^{8}$ El vestido de Celestina ya ha recibido la furia de Melibea, y ahora también la enemistad de Sempronio.

Finalmente, la unidad haldas vuelve a aparecer a finales del auto XI, cuando el negocio está prácticamente hecho. Celestina ha ido y venido, ha rememorado los días de prosperidad y a la vez ha remarcado su condición de vieja desamparada. Pármeno y Sempronio ya se han alejado discursivamente de la vieja, y ésta comienza a sentir nuevamente el cansancio que le producen sus haldas, y la Fortuna comienza a declinar su rueda: "¿Qué dezís desta esclava de Calisto? Toda la calle del Arcediano vengo a más andar tras vosotros por alcançaros, y jamás he podido con mis luengas haldas». (XI, 253)

En un inicio se planteó que el significado de las unidades léxicas depende, además de otros elementos, del momento textual en que sean enun-

8.- Esta cita ha sido tomada del aparato crítico que Russell realiza en su edición de la Celestina. Fernando de Rojas, La Celestina, Comedia o Tragicomedia de Calisto y Melibea, ed. de Peter E. Russell, Madrid, Castalia, 2001, nota 23, p. 346. 
ciadas. En el auto XI la tensión entre Celestina y Pármeno y Sempronio es ya muy evidente, y Calisto aún no le ha dado el manto que demandó en el auto vi.

Vemos pues, que los significados circunstanciales de las haldas están cosidos a acciones más profundas que la de vestir un personaje. Lo mismo sucede, pues, con las unidades que revisaremos a continuación.

\section{La Saya}

La saya $a^{9}$ es la unidad léxica más complicada, porque aparece literalmente entretejida a las unidades haldas y manto, además de que en algunas menciones parece desdibujarse con esta última. Tiene dos vertientes primarias. La primera se refiere a Celestina, y la segunda al resentimiento que Pármeno le tiene a ésta. La primera, podríamos decir, es la que ubicamos en el nivel de significado primordial, en el sentido de que confirma y recupera los significados circunstanciales de la unidad haldas, pero sobre todo, el de la segunda mención a las haldas, que como se dijo es piedra angular para este estudio. En la primera entrevista con Melibea (luego de que sus haldas se volvieran ligeras) Celestina nombra la unidad léxica saya por primera vez: "tu mala palabra será bíspera de una saya» (IV, 170). Esta mención da sentido a la segunda aparición de la unidad haldas y comprueba, efectivamente, el deseo de Celestina de vestido nuevo. Al respecto, Mariapia Lamberti opina: «El elemento del vestido está siempre presente, y juega un papel fundamental en la obra. Las malas artes de Celestina - y de los criados - tienen como uno de sus primarios efectos esperados el volverse a vestir». ${ }^{10}$

Pues bien, antes de entrar a casa de Calisto la vieja le dice a Sempronio: «¿Oyes Sempronio? De otro temple anda nuestro amo [...] No ay palabra de las que dize que no vale a la vieja Celestina más que una saya» (v, 180). Entre estas dos menciones, Celestina trae a colación los anteriores significados de las haldas en un mismo nivel. Palabra y vestido tienen ya una relación explícita. El significado circunstancial de la saya, pues, establece que las palabras de Celestina (y no son sólo las suyas, sino las de Melibea) tienen un valor, por lo que a continuación, dice: "Calla Sempronio, que

9.- La saya, se aclaró en la nota cuatro, era una prenda semi-interior. Más específicamente: "En los siglos XIII y XIV, este nombre (saya) se había dado a un vestido de hombre y a un vestido de mujer. Mediado el siglo Xv, se estableció la distinción entre el sayo de los hombres y la saya de las mujeres. La saya aparece desde entonces, como el nombre genérico del traje que las mujeres vestían directamente sobre la camisa, o sobre las faldillas o los corpiños interiores». (Carmen Bernis, Op. Cit., p. 120).

10.- Mariapia Lamberti, «El vestuario de La Celestina», en A quinientos años de La Celestina (1499-1999), ed. Sergio Fernández, coord. Carmen Elena Armijo, Colección Jornadas, México, Universidad Nacional Autónoma de México, 2004, p. 47. 
aunque haya aventurado mi vida, más mereçe Calisto y su ruego y tuyo, y más mercedes spero yo de él». (v, 180)

Bajo estas circunstancias, Celestina entra a darle las buenas nuevas a Calisto, acompañada de Sempronio. Y es aquí donde el significado de la unidad saya se complica, puesto que, si en este momento Celestina la usa como un recurso retórico para pedir su pago a Calisto, Pármeno encuentra en esta unidad la prueba de que Celestina los ha traicionado. El diálogo que se establece entre Pármeno y Celestina corre a la par que el que Celestina está teniendo con Calisto, y Pármeno puede descargar todo el resentimiento que tiene hacia Celestina en estos apartes, pues descifra los deseos de la vieja y pone bajo advertencia a Sempronio, quien toma en cuenta sus palabras porque a Celestina ya se le ha escapado aquello de la «partezilla».

El significado de la unidad saya, depende de los significados circunstanciales de la unidad haldas, y los posteriores que desarrollará la unidad manto, pues desde que Celestina comienza a hablar con Calisto una y otra unidad aparecen entretejidas como recurso retórico para resaltar su pobreza.

La función de esta unidad, en cuanto a Pármeno, es muy diferente, veamos el siguiente diálogo, en donde omitiremos las participaciones de Calisto para centrarnos en este diálogo indirecto que se establece entre Celestina y Pármeno:

Celestina. ¿Cuál mujer se vido en tan estrecha afrenta como yo? Que en tornallo a pensar se menguan y vazían todas las venas de mi cuerpo de sangre; mi vida diera por menor precio que agora daría este manto raído y viejo.

PÁrmeno. (Tú dirás lo tuyo; entre col y col lechuga, sobido as un escalón; más adelante te spero a la saya. Todo par(a) ti y no nada de que puedas dar parte. Pelechar quiere la vieja; tú me sacarás a mí verdadero y a mi amo loco. No le pierdas palabra, Sempronio, y verás que no quiere pedir dinero, porque es divisible.

Celestina. Buena se puede decir, pues queda abierta puerta para mi tornada, y antes me recibirá a mí con esta saya rota, que a otra con seda y brocado.

PÁrmeno. (Sempronio, cóseme esta boca, que no lo puedo sofrir; encaxado ha la saya).

Este diálogo es sumamente importante porque amplía los niveles de discurso en la obra y teje, además, el pasado de Celestina en el presente. Un pasado, por lo demás, que es de donde proviene todo el odio que Pármeno siente hacia la vieja, y que recupera en estos instantes. Momentos antes, Sempronio tejió su mala palabra a las haldas de Celestina; ahora, Pármeno comprueba sus sospechas por medio de la saya que ha pedido 
Celestina. Por otro lado, el diálogo que.... que Celestina está iniciando con Calisto cumple con las expectativas de la retórica clásica, en cuanto a que desarrolla elementos propios que están dirigidos a mover los ánimos en pro de un objetivo. La saya funciona aquí como un recurso retórico que potencia la imagen que Celestina quiere dar de sí misma, encaminada ésta a lograr su objetivo. Pero en la parte del discurso que corresponde a Pármeno y a Sempronio, Celestina ha cometido bastantes errores.

Después de esta escena, tiene lugar el encuentro entre Pármeno y Areúsa, gracias a esto, Celestina pensará que Pármeno se ha unido definit vamente a sus términos y que controla pues, su voluntad. Albert Lloret opina al respecto:

Por lo tanto, parece claro que Pármeno adopta el discurso de Celestina, se amolda a él, a sus argumentos, para proponer una justificación discursiva que le permita llevar a cabo sus propios fines, de acuerdo con las promesas de la vieja. Él, como Celestina, se sirve de las palabras confiándoles un valor simbólico y pervertible. La supuesta pericia dialéctica de la alcahueta solamente resulta contra Pármeno en tanto que cimentada en argumentos performativos, en promesas que determinan una consecución de determinadas acciones para poder conseguir otras. ${ }^{11}$

Así, cuando Pármeno está temporalmente bajo la voluntad de Celestina, le dice: «Tu saya y manto y aun mi sayo cierto está; lo otro vaya y venga, el quándo lo dará no lo sé». (Ix, 234)

Estas menciones a la unidad saya están directamente cosidas al devenir discursivo de Pármeno particularmente, puesto que él, además de adivinar las intenciones de Celestina, ha impedido que ésta obtenga su manto y saya. Y aunque durante esta mención parecería que ambas partes tienen el mismo objetivo, los intereses individuales tendrán más peso.

Terminemos este apartado con la siguiente mención, dice Calisto: «En lugar de manto y saya, porque no se dé parte a oficiales, toma esta cadenilla; ponla al cuello y procede en tu razón y mi alegría». (XII, 254) Calisto también entreteje las unidades manto y saya, y en este momento, la unidad saya no puede tener un significado circunstancial independiente, pues el objetivo que permanecía en el aire se transforma en un objeto que está presente y que cierra la acción. Rosario Ferré dice al respecto: «La entrega de la cadena de oro a Celestina por parte de Calisto, se refiere en primer lugar al cumplimiento del contrato entre ellos, y simultáneamente, al incumplimiento de contrato entre Celestina, Sempronio y Pármeno». ${ }^{12}$ En 
este instante, pues, entraremos de lleno a la parte del fracaso discursivo de Celestina, que es un recurso estilístico que pone en relieve la indigencia moral de la vieja, que ha iniciado en la segunda mención a sus haldas, ha continuado por las significados circunstanciales de la saya, y finalmente se ha materializado en el auto XII.

\section{El manto}

El manto ${ }^{13}$ es la unidad léxica que inicia y termina nuestro hilo discursivo. Los significados que arroja la unidad manto, no se refieren a una misma prenda, puesto que una es la que Celestina lleva puesta (el manto que pide a Sempronio; el que viste cuando habla con Calisto en el auto vi, y el que pide a Elicia al momento de su muerte), y otra la prenda ideal (aquel manto que queda fuera de los límites textuales, pues Celestina lo usó en un tiempo anterior a la acción, y aquel que el que pide a Calisto).

En su primera mención, en boca de Sempronio: «toma el manto y vamos» (I, 110) parecería que es un elemento ajeno a la acción. Es verdad que en este momento del texto no tiene mayor importancia, pero cobra valor significativo gracias a su última mención en el auto XII, pero ya llegaremos a eso. Que quede esta idea para retomar el significado general, y descubrir la tela perfecta del discurso celestinesco. A partir de aquí, dividiremos entonces las apariciones de la unidad manto no por orden de aparición, sino reconociendo los significados circunstanciales a partir del manto que Celestina lleva puesto, y la prenda ideal, que aún no existe o que ya no existe.

Para darle circularidad a nuestro argumento, tengamos en cuenta que Celestina una y otra vez insiste en un estado ideal perdido que ha quedado, por supuesto, en el pasado. En el auto IX, —el auto del resentimiento social- Celestina cuenta a Lucrecia:

[Que hombre avía, que estando diziendo missa] en viéndome entrar se turbaban, que no hazían ni dezían cosa a derechas. Unos me llamaban señora, otros tía, otros enamorada, otros vieja honrrada. Assí se concertaban sus venidas a mi casa, allí las ydas a la suya. Allí se me ofrescían dineros, allí promesas, allí otras dádivas, besando el cabo de mi manto, y aun algunos en la cara por me tener más contenta. (IX, 239)

13.- El manto, por su parte, era una prenda que iba por encima del atuendo completo. Las mujeres acomodadas poseían además uno o varios mantos para vestir en casa y era algo más corto que el de salir. El manto, con este nombre, era una prenda mayormente femenina. Las telas con las que se confeccionaban los mantos iban desde las más austeras, hasta una gran variedad de ricas telas. El manto se consideró, en el siglo xvi, un atuendo característicamente español. Véase, por ejemplo, James Laver, Breve Historia del traje y la moda, Madrid, Cátedra, 2008. 
Es indispensable comenzar el análisis de nuestra unidad manto por aquí, puesto que, en la segunda mención a sus haldas, el objetivo de Celestina era obtener un vestido nuevo. Éste supone un estado de gracia al que pretende regresar y que, como dice, un día tuvo. Celestina está en su última edad, y entendemos, cuando recuerda estos momentos, la motivación de la vieja para traicionar a sus confederados. Pues bien, dentro de este estado ideal, tenemos pues el momento que la vieja pide su pago a Calisto, o como diría Pármeno líneas atrás, «encaxado ha la saya»:

Celestina. Por un manto que tú des a la vieja, te dará en tus manos el mesmo que en su cuerpo ella traía.

Calisto. ¿Qué dizes de manto? Y saya y quanto yo tengo. Celestina. Manto he menester y éste terné yo en harto; no te alargues más. No pongas sospechosa dubda en mi pedir, que dizen que ofrecer mucho al que poco pide es especie de negar. (VI, 188, 189)

Este manto que promete Calisto, se mantiene en un nivel de ideal porque Celestina no lo obtiene en ese momento gracias a la intervención de Pármeno. Las circunstancias de esta petición son muy diferentes a las de su pasado, pues en este presente ella tiene que pedir su pago, mientras que en su estado anterior éste se le ofrecía.

Con Calisto, Celestina se encuentra en una situación comunicativa totalmente distinta. Las condiciones de diálogo deben de ser exactas, pensadas con precisión y recuperando, de algún modo, tradiciones discursivas del personaje de la alcahueta. La petición de manto teje, además, un hilo discursivo con las ropas de Melibea y trae a colación un significado totalmente sensual en contraposición con el que ha descrito de sí misma.

El manto que Celestina lleva puesto, por otro lado, funciona sobre todo, en el auto VI, como recurso retórico. Al inicio de este auto, Celestina describe su manto como raído, viejo, y lleno de agujeros. El manto al que se refiere es el que usa en el presente textual, que encuentra entonces un puente directo con el significado primordial de sus haldas. Puede ser o no que verdaderamente el manto esté en esas condiciones (no sería extraño que fuera una metáfora de su estado emocional y económico), pero la vieja lo particulariza porque necesita llevar la atención al estado de la prenda, para que cuando pida uno nuevo, la consecuencia sea lógica:

O mi señor Calisto, ¿y aquí estás? O mi nuevo amador de la muy hermosa Melibea, y con mucha razón, ¿con qué pagarás a la vieja que hoy ha puesto la vida al tablero por tu servicio? ¿Quál mujer se vido en tan estrecha afrenta como yo? Que en tornallo a pensar se meguan y vazían todas las venas de mi cuerpo de sangre; mi vida 
diera por un menor precio que agora daría este manto raído y viejo». (vi, 181)

Y también:

¿Pues a qué piensas que yva allá la vieja Celestina?, a quien tú demás de tu meresçimiento, magníficamente galardonaste? sino ablandar su saña, a sofrir su accidente, a ser escudo de tu absencia, a recebir en mi manto los golpes, los desvíos, los menosprecios, desdenes, que muestran aquellas en los principios de sus requerimientos de amor, para que sea después en más tenida su dádiva. (vI, 183)

Y nuevamente: «¿Debaxo de mi manto, dizes? ¡Ay mesquina, que fueras visto por treinta agujeros que tiene, si Dios no le mejora» (VI, 185). Esta última mención es harto importante, porque funcionará como metáfora de la parte fallida de su discurso, o sea, de todas las palabras que enunció sin seso alguno, y de todos los hilos discursivos que no llevó a buen puerto porque no vio que había los intereses individuales de Pármeno y Sempronio cosidos a sus palabras. Estas alusiones a la ropa raída aparecen encadenadas como recurso retórico y están dirigidas a Calisto. Recuperan significados de la unidad saya, tejidos al discurso de Pármeno, y generan el rompimiento de la confederación.

En la Celestina los tipos sociales, ya lo decía María Rosa Lida de Malkiel, son individuos luchando por su propio destino individual, y me parece que están construidos de manera en que, precisamente como una vida, no tengan una conciencia real de cuántos destinos se intersectan con el destino individual. Por esta intersección de discursos, Pármeno le ha quitado a Celestina la oportunidad de manto, y en cambio, Calisto le da una cadena "para que no se dé parte a oficiales» (XI, 254). Esta acción es por demás desgarradora, puesto que el poco valor que le significa la «cadenilla» a Calisto, a Celestina le significa salir de lazería: «Todo aquello alegra que con poco trabajo se ha gana, mayormente viniendo de parte de hombre tan rico que con los salvados de su casa podría yo salir de lazería, según lo mucho que le sobra» (IX, 235). Esta cadenilla significa que su ganancia es divisible y prefiere irse deprisa que cerrar cuidadosamente su discurso, porque a estas alturas la vieja ha perdido el seso totalmente.

Celestina ha pretendido establecer relaciones sintagmáticas al mismo nivel discursivo con Pármeno y Sempronio (es decir, ha querido establecer un canal comunicativo que permita mover los ánimos de ambos). Palabra y propósito no estaban cosidos con el mismo hilo y esto se ha notado en hechos extralingüísticos tales como el haldear, que encuentra su enlace con este momento en que la vieja se va de prisa. 
$\mathrm{Al}$ inicio de la obra, Celestina le dijo a Sempronio: "Los bienes, si no son communicados, no son bienes» (I, 119) y cuando trató de excusarse ante Sempronio por la "partezilla», dijo: "que parte o partezilla quanto tú quisieres te daré. Todo lo mío es tuyo: gozémonos y aprovechémonos, que sobre el partir nunca reñiremos» (v, 177). Estos enunciados cierran este trabajo porque presentan el discurso de Celestina como una metáfora de su manto lleno de hoyos, los mismos que tuvo en su discurso con respecto a la parte que correspondía a Pármeno y a Sempronio. Éstos, pues, ven en la cadenilla la parte divisible del negocio y su única oportunidad de lograr lo acordado en un inicio.

En el auto XII, conviven una serie de ironías que permiten cuestionarnos el valor de las unidades léxicas hasta aquí analizadas. La primera sucede a partir de que Celestina, una vez más, pretende burlar a sus confederados porque zurce un burdo hilo más a su pobre discurso y les dice que no sabe dónde está la cadenilla. Ambas partes tratan de mantener la compostura, pero poco a poco la sustancia de sus palabras sale a flote y sucede lo inevitable.

Sempronio, llevado por la ira, mata a Celestina, irónicamente, con un cuchillo. En la lucha por la vida y cuando todo discurso se ha liberado de máscaras estilísticas y discursivas, Celestina pide a Elicia su manto [“¡Elicia, Elicia, levántate dessa cama, dacá mi manto presto, que por los santos de Dios, por aquella justicia me vaya bramando como una loca! (XII, 277)], también irónicamente, sin obtenerlo. La primera aparición de la unidad léxica manto cobra importancia y se llena de significado en esta última mención gracias a que, en ese inicio, había una conveniencia de parte de Sempronio; ahora no. Ahora la vemos morir asesinada, clamando por su manto y por las autoridades, desnuda de sus atavíos de alcahuetería y terriblemente, con una voz que nadie escucha porque no existe nadie interesado en oírla. Celestina regresa al desamparo en el que inicia la obra, y muere sin vestido alguno, traicionada por sus propias palabras, por su «arreo» más brillante.

Una ironía más: líneas atrás, Calisto deseó haber estado debajo del manto de Celestina y ésta le remarca cuán agujereado está. Pues bien, además de que los agujeros discusivos que se encargó de dejar con Pármeno y Sempronio - veamos, por ejemplo, nuestra última aparición de la unidad manto, otra burla retórica de Celestina: «que de lástima que ove de verte roto pedí hoy manto a Calisto; no por mi manto, pero por que, estando el sastre en casa y tú delante sin sayo, te le diesse» (VII, 199)—, después de la muerte de Celestina, el negocio saldrá a la plaza. 


\section{Conclusión}

Las haldas acompañan a Celestina, el manto la traiciona. Retomemos entonces la idea de textum. Los hilos que la vieja usó para urdir sus discursos con Pármeno y Sempronio son burdos, se notan irremediablemente en la tela de su discurso, como los hilos burdos de sus propias haldas.

Ni qué decir que su primer oficio, según Pármeno, es el de labrandera o de que constantemente haya referencias al vestido-oficio de Celestina, y de que la obra esté plagada de sentencias o proverbios referentes al vestido. Mucho más profundamente, podemos preguntarnos quién es Celestina; si es la alcahueta maestra de la palabra a la que como lectores nos aferramos, o si bien es una vieja avarienta y sedienta de oro como la misma obra nos la dibuja. Lejos quedaron las grandes sagas en donde los siervos vestían a la par que sus señores, o por lo menos encontraban cobijo en ellos.

Esta obra se teje sobre la palabra perdida de Calisto y cómo Celestina la recupera, pero que le cuesta la vida de una manera terrible. Entonces las unidades léxicas se convierten, bajo los parámetros de significado analizados, en unidades de caracterización, porque el manto es para Celestina una necesidad espiritual, es decir, la causa se convierte en efecto. 


\section{Bibliografía}

Alcalá Galán, Mercedes, "Voluntad de poder en Celestina», Celestinesca 20 (1996): 37-55.

Bernis, Carmen, Trajes y modas en la España de los Reyes Católicos, Madrid, Instituto Diego Velázquez del Consejo Superior de Investigaciones Científicas, 1979

- Indumentaria española en tiempos de Carlos V, Madrid, Instituto Diego Velázquez del Consejo Superior de Investigaciones Científicas, 1962.

Boucher, François, Historia del traje en occidente. Desde la antigüedad hasta nuestros días, México, Gustavo Gili, 2000.

Cantalapiedra, Fernando, Lectura Semiótico-formal de La Celestina, Kassel, Reichenberger, 1986.

Correas, Gonzalo, Vocabulario de refranes y frases proverbiales (1627), ed. de Louis Combet, Madrid, Castalia, 2000.

Coseriu, Eugenio, Introducción a la lingüística, Madrid, Gredos, 1986.

Covarrubias, Sebastián de, Nuevo tesoro de la lengua castellana o española, ed. de Felipe R. Maldonado, Madrid, Castalia, 1995.

Ferré, Rosario, "Celestina en el tejido de la Cupíditas», Celestinesca 7 (1983): 7-14.

Gilman, Stephen, La Celestina: arte y estructura, Madrid, Taurus, 1974.

LAmberti, Mariapia, "El vestuario de La Celestina», en A quinientos años de La Celestina (1499-1999), ed. Sergio Fernández, coord. Carmen Elena Armijo, Colección Jornadas, México, Universidad Nacional Autónoma de México, 2004, pp. 45-58.

Laver, James, Breve Historia del traje y la moda, Madrid, Cátedra, 2008.

Lida DE MALKIEL, María Rosa, La originalidad artística de La Celestina, Buenos Aires, EUDEBA, 1962.

LuRIE, Alison, El lenguaje de la moda. Una interpretación de las formas de vestir, Barcelona, Paidós, 1994.

Miaja de la Peña, María Teresa, "'Agora que voy sola...' en boca de Celestina», Olivar: revista de literatura y culturas españolas 11 (2008): 27-37.

RojAs, Fernando de, La Celestina, Ed. de Dorothy S. Severin, Madrid, Cátedra, 2008.

- La Celestina. Comedia o Tragicomedia de Calisto y Melibea, Ed. de Peter E. Russell, Madrid, Castalia, 2001.

SHIPLey, George A., "El natural de la raposa', un proverbio estratégico de la Celestina.", Nueva Revista de Filología Hispánica XIII (1974): 35-64.

Snow, Joseph T. "Quinientos años de animadversión entre Celestina y Pleberio: postulados y perspectivas», en Visiones y crónicas medievales. 
Actas de la VII Jornadas Medievales, eds. Aurelio González, Lillian von der Walde y Concepción Company, México, Universidad Nacional Autónoma de México-Universidad Autónoma Metropolitana-El Colegio de México, 2002, pp. 13-29. 


\section{Palma Villaverde, Mariel Aldonza, «El hilo del que está tejido el manto de Celestina», Celestinesca 37 (2013), pp. 101-118.}

\section{RESUMEN}

La Celestina es una obra con múltiples hilos discursivos. Este trabajo analiza el que se construye mediante las unidades léxicas haldas, saya y manto de Celestina. Éstas tienen diferentes funciones discursivas en la obra, cada una con distintos significados, los cuales derivarán en uno solo, que es el fracaso discursivo de la alcahueta. Gracias a estas unidades, pues, se podrá observar a una Celestina preocupada por adquirir un manto nuevo, como único bien que la llevará, otra vez, a ese estado de prosperidad que un día tuvo. Aunque su "arreo» más brillante sean sus palabras, irónicamente, éstas le fallarán en el auto XII.

PALABRAS ClaVE: Celestina, hilo discursivo, unidad léxica, haldas, saya, manto, función discursiva, significad .

\section{ABSTRACT}

Celestina is a masterpiece with multiple discursive threads. The present work tries to analyze one of them, namely the one built from lexical units related to attire: petticoat, cloak, and Celestina's kirtle. Although these units play different roles along the drama, their different local connotations can be seen to converge to a common, global implication, which is the discursive failure of Celestina. For instance, by following the trajectory of these units we can observe a Celestina worried by the prospect of acquiring a new cloak, the only good, she reckons, able to send her back to that past of prosperity she once had. Even if her words are her brighter «dress», ironically, these will betray her, in the twelfth act.

KEY WORDS: Celestina, discursive thread, lexical unit, petticoat, cloak, kirtle, discurse function, meaning.

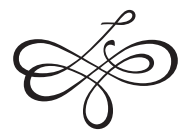

